\title{
Implementing the Sustainable Development Goals for Quality Education in Institutions of Higher Education in Pakistan: A Qualitative Analysis
}

\author{
Shazia Noureen $^{1}$, Bashir Hussain ${ }^{2}$, Khalid Khurshid ${ }^{3}$
}

\begin{abstract}
The Millennium Development Goals (MDGs) markedly focused on access to education for all through poverty elevation. All nations and especially developing countries like Pakistan had responded positively to achieve these MDGs. Afterward, UNO announced sustainable development goals(SDGs) agenda of 2030 , fourth goal of which was about the quality of education in higher education institutes (HEIs).In this relation, the focus of present research was to analyze current implementations by institutes of higher education for imparting "quality education to promote life-long learning for all" under guidelines of the Higher Education Commission (HEC) of Pakistan. Therefore, it is important to ensure sustainability in providing quality education to future generations. For conducting this study, a qualitative approach was adopted to get opinions from the heads of departments about measures taken for sustainability. Population of this study comprised all the heads of the departments from all faculties of Bahauddin Zakariya University, Multan, Pakistan. Whereas, sample consisted nineteen (19) heads from Faculty of Arts and Social Sciences, using purposive sampling technique. For data collection purposes, an open-ended semi structured interview protocol was developed, consisting of six questions. Thematic analysis technique was adopted to analyze the opinions of all heads of the departments to achieve SDGs to enhance quality of higher education. Results of study showed that most heads agreed to implement sustainable goals at university level within their capacity. Moreover, the lack of resources and expertise were the major obstacles for implementing these goals in their institutes.
\end{abstract}

Keywords: Sustainable Development Goals, Quality Education, Higher Education

\footnotetext{
${ }^{1} \mathrm{PhD}$ Scholar, Department of Education, Bahauddin Zakariya University, Multan

${ }^{2}$ Assistant professor, Department of Education, Bahauddin Zakariya University, Multan Email: bashirhussain@bzu.edu.pk

${ }^{3}$ Chairman, Department of Education, Bahauddin Zakariya University, Multan.

Email: khalidkhurshid@bzu.edu.pk
} 


\section{Introduction}

The Millennium Development Goals (MDGs), introduced in 2000, observed significance progress to achieve the target of access education for all though poverty elevation. World nations had responded positively to achieve these MDGs for the overall progress of their countries and especially developing countries like Pakistan. But issue of quality in education was remained unanswered (Tanaka \& Taguchi, 2019), even children have attended school but their learning was not up to the standard of education in developed countries. Likewise, many children were unable to read the simple reading and having no numeracy skills to solve simple mathematical calculations after some years of attending schools. It was challenging situation for all nations and especially for developing nations like Pakistan, i.e., the issue of quality education for teachers and their students. It was badly needed the sustainability for the future generations.

Considering this background, sustainable development was clearly defined, and it refers to the development that meets the needs of the present without compromising ability of future generations to meet their own needs". Moreover, Paul and Didham (2014) are of view that sustainable development in education is mostly used as synonym with quality in education to bring long lasting changes in the education system. According to Moyer and Hedden (2020), "The SDGs were considered as central element of major development plans and maximize foreign aid strategies to achieve sustainability"(p.26).In this context, this research was based on identifying progress to implement sustainable development goals agenda for improving the quality of education as is mentioned in the fourth goal of Sustainable development agenda of United Nation.

Considering the importance of SDGs for the development of the country, Parliament of Pakistan has also adopted these sustainable development goals (SDGs) as their national goals in early 2016 (Siddiqui, 2018). Furthermore, planning commission of Pakistan is effectively coordinating partnership between private and public sector and with civil society to achieve success for sustainable development goals (SDGs). The present research was addressing the following research question that 'How can quality education reinforce sustainable growth in the Pakistani context'. In this modern era, the term quality education is a focus of attention of all nations world-wide. It is also important for educational institutions to become provider of quality education to produce best graduates to serve the country and help social, economic, political and moral development of their country.

In the development perspective of any country, quality education has more significant impact on the overall progress of the country and especially 
(Ali, 2018), in Pakistani context, the more capital or investments are allocated for higher education institutions but in return quality education is a big challenge for all stakeholders. Furthermore, Pakistan (2017) stated that from 2002 higher education is governed by HEC through a series of 5-year reform plans. In this context, between $2010-2015$, there is $174 \%$ increase in the student enrolment at the higher education level but the funding for higher education remains low and not at par with the international standards. Nhamo and Mjimba (2020) explained the view of world leaders that why they adopted sustainable development goals as a part of 2030 agenda to providing knowledge based economy to end poverty and to fight against inequality to maintain social justice for the people of developing countries of the world. Likewise, the equitable quality in education is more concerned about that the good education is always helpful to achieve other goals for sustainable development agenda.

It is also noticeable fact that the lack of quality education is due to the lack of adequately trained teachers, week curricula and practices, and government investments to run institutions with success. For quality education, investments play a major role to train their teachers by conducting seminars/workshops and provide opportunities for their professional growth is an important. The SDG4's important target for equitable quality education is given (UNSDG4, 2015). As De Leo (2012) have done content analysis international documents that what is needed to add at this time is the values-based approaches for sustainable development which help to develop learners value like emotional, physical, moral, social and spiritual.

Furthermore, the SDGs (2015-2030) clearly state that "By 2030, ensure that all learners acquire knowledge and skills needed to promote sustain-able development, including, among others, through education for sustainable development and lifestyles, human rights, gender equality, promotion of culture of peace and non-violence, global citizenship and appreciation of cultural diversity for sustainable development of a country". Furthermore, Peng, McNess, Thomas, Wu, Zhangand Tian (2014) suggested that trained teachers can contribute in more way than newly appointed less experience teachers. In addition, Knoeppel, Logan and Keiser (2005) also have view for the quality teaching, faculty matters, and training is mandatory for sustainable development. Therefore, Government of Pakistan have categories SDGs priorities and they put "equitable quality in education" for sustainable development in first category to make sure to keep on agenda to develop immediate relevant policy (Government of Pakistan, 2018). Furthermore, the Higher Education Commission of Pakistan has shown concerns over achieving the SDGs to synchronous with the United Nation decision of September 2015. 
Quality sustainable education is highly considered backbone to take developing nations to compete with the existing education standards of advanced countries. Therefore, researchers were keen to conduct this study related to quality in education for sustainable development. Moreover, our national priority on SDGs indicators is also expecting least minimum training (i.e., pedagogical training) for in service or pre-service training required for the every level of education and improve the existing curricula used by the institutes of higher education.

\subsection{Objectives of the Study}

The main objective of the research was to explore the fourth $\left(4^{\text {th }}\right)$ theme of sustainable development goal i.e., equitable quality education to promote lifelong learning for all. In this connection, this research was focused on exploring current progress in implementing the sustainable development goals agenda to ensure the quality education in institutions of higher education in Pakistan. Specifically, this study was focused on achieving following objectives.

1. To explore the progress in implementing quality education goals with reference to sustainable development goals through enriching curricula and organizing teacher training activities for imparting quality education in higher education institutions of Pakistan.

2. To identify barriers in providing the equitable quality education at higher education institutions of Pakistan for sustainable development, through improved curricula and practice-based training to faculty.

\subsection{Significance of the Study}

The most significant beneficiary of this study would be the HEC of Pakistan to adopt some suggested measures to enhance quality of HEIs with reference to achieve sustainable development goals agenda of United Nations. The research would also be helpful for HEIs of Pakistan to take concrete measures to ensure the quality of education by improving their curricula and practices through their faculties for sustainable development of institutions of higher education in Pakistan. This research may ultimately help the students of higher education as end users to receive the benefits of the quality education.

\section{Literature Review}

Presently, the society is facing a range of global issues like educational, economic, social, and cultural, which are essential for the progress of any nation to keep them at par with the other developed nations (Rieckmann, 2012). Furthermore, goals of lifelong learning through quality education for sustainability is major focus after development of SDGs in September 2015 as an agenda of the United Nations to support developing countries of the world and to 
meet future challenges especially through providing quality education. As education is a key factor to serve as a tool to develop the whole structure of the country for sustainability for taking the nations to compete other technologically advanced nations. Furthermore Kalsoom, Qureshi and Khanam (2018) has stressed upon the "Building Knowledge Competencies" for sustainable development in Pakistan among other Asian countries. Their study also indicated that to keep the country in race for development with other Asian countries, quality higher education can play a vital role to produce skilled human resources for achieving sustainable development through education.

Furthermore, Zaidi, Mirza, Hou and Ashraf (2019) also argued that among UN seventeen Sustainable Development goals (SDGs), the followings were the top priority areas like health, economic growth, quality education, communities and climate control by implementing these important areas in their agenda. It is therefore, it becomes inevitable goals for the countries like Pakistan to implement sustainable procurement which help to reduce health, energy and environmental costs by introducing modern technology through advancing quality education for future generations. Ramos, Caeiro, Van Hoof, Lozano, Huisingh and Ceulemans (2015) suggested that HEIs can play their potential roles in transforming societies to achieve these goals for sustainability.

For this purpose, HEIs can also incorporate environmental education and education for the sustainable development into their curricula for providing awareness at higher education level. Moreover, it is now highly important to make sustainable development as an integral part of all higher education institutions to work under the umbrella of HEC to encourage on-campus sustainable life experiences and also to 'Educate the Educators' by providing upto date training to improve teaching learning process along with improving existing curricula. While in view of Khan and Khan (2018), sustainable development in higher education is still nascent stage and aim was to provide sustainable future to our young generation for ensuring their participation as leader to lead country in all sorts of important venues like environment, economic, social and powerful culture.

During the last decade, massive investments have already been made across the world to enhance the competencies that help improving social outcomes through quality education. Therefore, fourth goal of the United Nations' Sustainable Development Goals is about quality education and UN had suggested 10 targets to achieve sustainable development goals which represent universal agenda to develop better skills for better lives. Out of these ten (10), the five (05) targets are concerned with improving and enhancing the quality of education for the individual children, young people and adults, and also to give 
them better and more relevant knowledge and skills through institutions. It also gives more importance to the role of higher education institutions of Pakistan to keep eye on overall development done around the world to cope with new emerging challenges.

\subsection{Research Design}

\section{Research Methodology}

To achieve the objectives of the present research study, qualitative research design was adopted. Furthermore, this research design was strengthened by using triangulation design. The research was completed in two phases, and both conducted at the same time in a parallel way and using triangulation mixed methods research design (Briedenhann \& Wickens, 2005; Creswell, 2007). At the same time, this study also used case study design as the data were collected from Bahauddin Zakariya University, as a case.

\subsection{Population}

For conducting this study, all faulty members from Faculty of Arts and Social Sciences and Faculty of Islamic Studies and Languages of the Bahauddin Zakariya University, Multan were selected as a population.

\subsection{Sample and Sampling Techniques}

For selection of sample, firstly Bahauddin Zakariya University, Multan was selected as a case. Second, the nineteen departments from Faculty of Arts and Social Sciences and Faculty of Islamic Studies and Languages were purposefully selected. Third, curricula of one under-graduate program from the nineteen departments of both faculties was purposefully selected. Finally, the nineteen Heads of Departments from the both faculties were selected as a sample, using the purposive sampling technique for conducting in-depth interviews.

\subsection{Instrumentation}

For the first phase of study, the curricula of one under-graduate program from nineteen departments of both faculties was taken from program coordinators of respective programs. For the second phase of study to conduct interviews from nineteen Heads of the Departments, semi-structured interviews were designed for exploring their views about enriching curricula and their current practices for imparting quality education with reference to SDGs. For this, an interview schedule was developed to explore current practices for training program and in teaching of curricula. Focus of semi-structured interviews was on exploring views of Heads of the Departments about whether curricula and teaching practices ensure that all learners acquire knowledge and skills needed to promote sustainable development. Interviews further focused on exploring practices for emphasis on education for sustainable development and 
sustainable lifestyles, human rights, promotion of non-violence and peace culture, gender equality, global citizenship, appreciation of cultural diversity and contribution of culture to sustainable development.

\subsection{Data Collection}

For data collection in first phase of study, curricula of one undergraduate programs from nineteen departments of both faculties was taken from the program coordinators of respective programs. For second phase, semistructured interviews were conducted from nineteen Heads of Departments about whether curricula and teaching practices ensure that all learners acquire knowledge and skills needed to promote sustainable development. Interviews further focused on exploring curricula and practices for emphasis on education for sustainable development and sustainable lifestyles, human rights, promotion of non-violence and peace culture, gender equality, global citizenship, appreciation of cultural diversity and contribution of culture to sustainable development.

\section{Data Analysis and Interpretation}

For exploring curricula of one under-graduate program of both faculties from perspective of quality education of the sustainable development goals in the first phase of the study, both thematic analysis and content analysis techniques were used. Focus of content analysis was on exploring seventh target of quality education for SDGs. The analysis particularly focused on exploring the themes in curricula of one undergraduate programs in nineteen departments about the about the extent to which curricula ensure that all learners acquire knowledge and skills needed to promote sustainable development. The analysis also focused on exploring the curricula for emphasis on education for sustainable development and lifestyles, human rights, promotion of nonviolence and peace culture, gender equality, global citizenship, appreciation of cultural diversity and culture's contribution to sustainable development. Thematic analysis was helpful in identifying themes and content analysis was useful in calculating frequency of emerged themes. Both content and the thematic analyses strengthened the results of the study and ensured the reliability and validity.

For analysis of interviews to explore views of Heads of the Departments from perspective of quality education of SDGs, both thematic analysis and content analysis techniques were used. For this purpose, first initial coding was done with the data and then subthemes were developed, followed by main themes. In addition to the development of sub-themes and main themes, number of themes were also counted, which lead to process of content analysis. This was done as per guidelines provided by Creswell (2012). Thematic analysis was 
guided by the work of Braun and Clarke (2006) and evidence method used by Yin's (2003) was adopted for the results of the responses provided by the respondents. For reliability and validity, inter-rater or inter-scorer method was used, and analysis was first done by researchers individually and then was shared in the team.

The results of this study have been presented in three parts. First part of results is related to thematic analysis of curricula, while the second and the third part present results emerged from thematic and content analysis of interviews and were related practices and problems and issues with references to imparting quality education from perspective SDGs. Results related to thematic analysis of curricula found four main themes for imparting quality education with reference to SDGs. Table 1 presents list of main themes, as emerged from thematic analysis and content analysis of curricula of under-graduate programs and interviews from heads of the departments.

Table 1

List of main themes, as emerged from the analysis of curricula and interviews

\begin{tabular}{|c|c|c|}
\hline S\# & Areas of Analysis & Main Themes \\
\hline 1. & $\begin{array}{l}\text { Analysis of the Curricula of } \\
\text { Undergraduate Programs } \\
\text { from Nineteen Departments }\end{array}$ & $\begin{array}{l}\text { Curricula are lacking international standards. } \\
\text { Outdated course outlines/content of curricula. } \\
\text { Limited resources in curricula and lack variety. } \\
\text { Less use of technology in content and resources. }\end{array}$ \\
\hline 2. & $\begin{array}{l}\text { Analysis of In-Depth } \\
\text { Interviews from the } \\
\text { Nineteen Heads of the } \\
\text { Departments }\end{array}$ & $\begin{array}{l}\text { Teaching practices are not up to the mark. } \\
\text { Reviews/evaluation and change in curricula. } \\
\text { Lack of integration of technology in teaching. } \\
\text { Lack of resources in imparting quality education. }\end{array}$ \\
\hline 3. & $\begin{array}{l}\text { Analysis of the Curricula of } \\
\text { Undergraduate Programs } \\
\text { and In-Depth Interviews } \\
\text { from Nineteen Departments }\end{array}$ & $\begin{array}{l}\text { Curricula and practices are lacking focus on } \\
\text { ensuring that all learners acquire the knowledge } \\
\text { and skills needed to promote sustainable } \\
\text { development. } \\
\text { Curricula and practices are lacking focus } \\
\text { sustainable lifestyles and human rights. } \\
\text { Curricula and practices are lacking focus } \\
\text { promotion of non-violence and peace culture. } \\
\text { Curricula and practices are lacking focus on gender } \\
\text { equality, global citizenship, appreciation of } \\
\text { cultural diversity and contribution of culture to } \\
\text { sustainable development }\end{array}$ \\
\hline 4. & $\begin{array}{l}\text { Problems and Issues in } \\
\text { Imparting Quality Education } \\
\text { with Reference to } \\
\text { Sustainable Development }\end{array}$ & $\begin{array}{l}\text { Lack of infrastructure to impart quality education. } \\
\text { Lack of provision of funding. } \\
\text { Lack of qualified/trained faculty members. }\end{array}$ \\
\hline
\end{tabular}


First theme emerged from thematic and content analysis of curricula found that curricula are not as per international standards in $61 \%$ of the programs. Second theme found the course outlines and content of curricula are not updated in $57 \%$ of programs. The contents of most parts of programs are outdated and need revisions and changes. Likewise, list of references is also outdated and limited. The third theme found that both curricula and practices are lacking in areas related to sustainable development. Fourth theme found that resources in curricula are limited and lack variety in $71 \%$ programs. There is a need to include diverse resources in curricula. The final theme found that there is less use of technology in content and resources of curricula.

The first theme emerged from thematic analysis and content analysis of interviews found that teaching practices for teaching of curricula are not up to the mark in $37 \%$ departments. Only $20 \%$ heads were able to modify curricula following international standards. However, eighty percent $(80 \%)$ Heads have started thinking over modifying curricula of their programs. Furthermore, the Heads are of the view that modifying curriculum is difficult without trained faculty members. Majority of heads (83\%) complained about the shortage of foreign qualified trained faculty members to help other faculty members.

The second theme emerged from thematic analysis and content analysis of interviews was related to change in curricula related to theme of quality education from the perspective of sustainable development goals and their attitudes towards implementing these changes. It was found that only $29 \%$ heads teachers having clear perception about the change in curriculum to achieve the goals of quality education. They further disclosed that they have also motivated teachers in their respective departments to attain quality teaching practices. These findings also revealed that most of the heads $(77 \%)$ were having positive perceptions and attitudes to implement changes in curricula to improve their existing curriculum in relation to sustainable development goals.

Third theme found that both the curricula and practices are lacking in focus on ensuring that all learners acquire knowledge and skills needed to promote sustainable development. It further found that curricula and practices are lacking in focus on sustainable lifestyles and human rights. Furthermore, the curricula and practices are lacking focus promotion of non-violence and peace culture. Likewise, curricula and practices are lacking in focus on gender equality, global citizenship, and appreciation of cultural diversity, along with the contribution of the culture to sustainable development

The fourth theme emerged from thematic analysis and content analysis of interviews of nineteen heads of the departments was related to integration of technology in teaching. It was found that heads of the departments perceive that 
$79 \%$ teachers do not integrate technology in teaching. Final theme emerged from analysis of interviews was related to the resources and they perceive that the lack of resources is main hurdle in imparting quality education in their departments. Most respondents (73\%) were further of the view that it is the responsibility of Higher Education Commission of Pakistan to provide material and human resource to train the faculty members for the sustainable progress of the students.

The Heads of Departments were further inquired about issues and problems in imparting quality education in relation to sustainable development goals. The first theme emerged from thematic and content analysis of interviews was related to lack of infrastructure for imparting quality education. Most of the heads $(81 \%)$ perceived that the lack infrastructure is the main problem in making positive changes in their departments, which ultimately may help in providing quality education for sustainable development in higher education institutions.

The second theme emerged from thematic and content analysis of interviews about issues and problems in imparting quality education in relation to sustainable development goals was related to the lack of provision of funding. Majority of respondent ( $80 \%$ ) have opinion about lack of provision of funding as major barrier to achieve sustainable development goals. The final theme related to the issues and problems in imparting quality education in relation for sustainable development goals was the lack of qualified faculty members. It was found that $43 \%$ heads of the departments perceive that the lack of foreign qualified and the competent faculty members is the main problem in imparting higher education institutions for providing quality education.

This study also found that most heads (83\%) have positive attitude towards contributing in improving their existing curricula of different programs offered in departments. Majority of the heads $(79 \%)$ were convinced to provide training to their faculty members, provided HEC ensures funds and human resources to help them. This will help departments to train their faculty members to use modern technologies and e-learning methods to make teaching learning process more attractive for their students.

\section{Discussion and Conclusion}

The conclusions of the present research study were based on the objectives of this study that how institutions of higher education in Pakistan were responding to enhance the quality of higher education in keeping the idea of sustainable development goal agenda, specially designed for the developing countries of the world. It was concluded that most of the heads of the institutions of higher education are responding positively towards improvement in their existing curricula for different programmes under their supervision. It was further concluded that most of the heads were motivating their faculty members to 
incorporate new content and integrating technology in their teaching and learning process to achieve the goal of quality education for sustainable development in education and to cope future challenges. For this, Lozano, Huisingh and Ceulemans (2015) suggested that HEIs can play their potential roles in transforming societies to achieve these goals for sustainability.

This study concluded that the contents of the most parts of the programs are outdated and need revisions and changes. Likewise, list of references is outdated and limited. Resources in curriculum are limited and lack variety. It was also concluded that teaching practices for teaching of curriculum are not upto the mark. Furthermore, it was also concluded that the head teachers are facing difficulties in modifying curricula of their programs without trained faculty members. For this, Peng, McNess, Thomas, Wu, Zhang, and Tian (2014) suggested that trained teachers can contribute in more effectively than newly appointed less experience teachers. It was further concluded that only $29 \%$ Heads teachers have clear perception about the change in curriculum to achieve the goals of quality education. It was also concluded that most of the heads of departments were having positive perceptions and attitudes to implement changes in curricula to improve their existing curriculum in relation to SDGs.

This study also concluded that most of the heads of the departments intend to provide trainings to their faculty members to update and refresh their knowledge and skills to meet the international standards at par. Heads of departments also intend to fulfill new emerging needs to equip their faculty members with online teaching skills, which have far more reaching impact on overall education of country and higher education problems. It was also concluded that there is also a need to train faculty members in using on-line resources for engaging their students with courses. In this connection, Knoeppel, Logan and Keiser (2005) also have view for quality teaching, faculty matters, and training is mandatory for sustainable development. It was, however, also concluded that most of heads of departments indicated the lack of provision of funds and technological resources as the major hurdles for sustainability.

\section{Recommendations}

This study found that the contents of the most parts of programs are outdated and need revisions and changes. Likewise, the resources in curriculum are limited and lack variety. It is, therefore, recommended for teachers and academic leaders to include diverse resources in curricula. This study further found that most of heads of departments indicated the lack of provision of funds and technological resources as the major hurdle for sustainability. It is, therefore, recommended that the HEC may provide the funding for provision of resources 
and in turn, universities can upgrade their resources and learning management systems (LMS) to deliver their education uninterrupted in any situation and enhance sustainability in education from present and future perspectives.

The findings of the current study are based on in-depth interviews of only nineteen (19) Heads of the Departments from two faculties of the Bahauddin Zakariya University Multan, Pakistan. It is, therefore, recommended to increase sample size to get more comprehensive opinions from the heads of departments from other faculties and, also increase the number of universities. For generalization of the results of this present study, quantitative survey can also be included. Moreover, interview schedule in this study consisted on only six open ended questions. It is recommended to add more questions to get relevant information. Furthermore, this study was limited only to the public sector universities without surveying private sector higher education institutes. The private higher education institutions may also be included in the future studies. Likewise, future studies could be done in colleges, higher running under the affiliation of the higher education institutions of Pakistan.

\section{References}

Ali, M. (2018). Education quality improvement from the perspective of sustainable development. Proceeding book, third international seminar, 175-191.

Creswell, J. W. (2007). Five qualitative approaches to inquiry: Qualitative inquiry and research design. Sage Publishing.

Creswell, J. W. (2012). Educational Research: Planning, Conducting, and Evaluating Quantitative (pp. 146-166). Upper Saddle River, NJ: Prentice Hall.

De Leo, J. (2012). Quality education for sustainable development. UNESCO APNIEVE Australia

Franco, I., Saito, O., Vaughter, P., Whereat, J., Kanie, N., \& Takemoto, K. (2019). Higher education for sustainable development: actioning the global goals in policy, curriculum and practice. Sustainability Science, 14(6), 1621-1642.

Idowu, S. \& Peter, R. Z. (2019). The future of United Nations sustainable development goals CSR Sustainability ethics and governance. Chan Switzerland Springer, l(2), 117-127. 
Kalsoom, Q., Qureshi, N., \& Khanam, A. (2018). Perceptions of the Research Scholars Regarding Education for Sustainable Development (ESD) in Pakistan. In Sustainable Development Research in the Asia-Pacific Region (pp. 165-179). Springer.

Khan, S., \& Khan, A. M. (2018). A Phenomenological Study of Education for Sustainable Development in Higher Education of Pakistan. Pakistan Journal of Education, 35(2), 117-136.

Knoeppel, R. C., Logan, J. P., \& Keiser, C. M. (2005). Measuring Teacher Quality: Continuing the Search for Policy-Relevant Predictors of Student Achievement. Online Submission.

Moyer, J. D., \& Hedden, S. (2020). Are we on the right path to achieve the sustainable development goals? World Development, 127, 1047-49.

Nazar, R., Chaudhry, I. S., Ali, S., \& Faheem, M. (2018). Role of Quality Education for Sustainable Development Goals (SDGS). PEOPLE: International Journal of Social Sciences, 4(2).

Nhamo, G., \& Mjimba, V. (2020). Sustainable Development Goals and Institutions of Higher Education. Springer.

Paul, O. M., \& Didham, R. J. (2014). Quality Education for Sustainable Development: A priority in achieving sustainability and well-being for all. Institute for Global Environmental Strategies.

Peng, W. J., McNess, E., Thomas, S., Wu, X. R., Zhang, C., Li, J. Z., \& Tian, H. S. (2014). Emerging perceptions of teacher quality and teacher development in China. International Journal of Educational Development, 34, 77-89.

Ramos, T. B., Caeiro, S., Van Hoof, B., Lozano, R., Huisingh, D., \& Ceulemans, K. (2015). Experiences from the implementation of sustainable development in higher education institutions: Environmental Management for Sustainable Universities. Journal of Cleaner Production, 106, 3-10.

Rieckmann, M. (2012). Future-oriented higher education: Which key competencies should be fostered through university teaching and learning? Futures, 44(2), 127-135.

Siddiqui, S. A. (2018). Sustainable Development Goals (SDGs). Ministry of Planning. Islamabad. 
Zaidi, S., Mirza, F., Hou, F., \& Ashraf, R. (2019). Addressing the sustainable development through sustainable procurement: What factors resist the implementation of sustainable procurement in Pakistan? Socio-Economic Planning Sciences, 68, 100671. doi: 10.1016/j.seps.2018.11.008

\section{Citation of this Article:}

Naureen, S., Hussain, B., \& Khurshid, K. (2020).Implementing the Sustainable Development Goals for Quality Education in Institutions of Higher Education in Pakistan: A Qualitative Analysis. International Journal of Innovation in Teaching and Learning (IJITL), 6(1), 159-173. 